\title{
Salinity Tolerance of Two Potato Cultivars (Solanum tuberosum) Correlates With Differences in Vacuolar Transport Activity
}

\author{
Rinse Jaarsma* and Albertus H. de Boer* \\ Faculty of Earth and Life Sciences, Vrije Universiteit Amsterdam, Amsterdam, Netherlands
}

OPEN ACCESS

Edited by:

Sonia Negrao,

King Abdullah University of Science and Technology, Saudi Arabia

Reviewed by:

Rhiannon K. Schilling,

University of Adelaide, Australia

Eduardo O. Leidi,

Consejo Superior de Investigaciones

Cientificas (CSIC), Spain

*Correspondence:

Rinse Jaarsma

rinse.jaarsma@gmail.com

Albertus H. de Boer

a.h.de.boer@vu.nl

Specialty section:

This article was submitted to

Plant Abiotic Stress,

a section of the journal

Frontiers in Plant Science

Received: 05 March 2018

Accepted: 15 May 2018

Published: 05 June 2018

Citation:

Jaarsma R and de Boer AH (2018)

Salinity Tolerance of Two Potato

Cultivars (Solanum tuberosum)

Correlates With Differences

in Vacuolar Transport Activity.

Front. Plant Sci. 9:737.

doi: 10.3389/fpls.2018.00737
Potato is an important cultivated crop species and since it is moderately salt sensitive there is a need to develop more salt tolerant cultivars. A high activity of $\mathrm{Na}^{+}$transport across the tonoplast in exchange for $\mathrm{H}^{+}$is essential to reduce $\mathrm{Na}^{+}$toxicity. The proton motive force (PMF) generated by the $\mathrm{V}-\mathrm{H}^{+}$-ATPase and the $\mathrm{V}-\mathrm{H}^{+}$-PPase energizes the $\mathrm{Na}^{+}\left(\mathrm{K}^{+}\right) / \mathrm{H}^{+}$antiport. We compared the activity, gene expression, and protein levels of the vacuolar proton pumps and the $\mathrm{Na}^{+} / \mathrm{H}^{+}$antiporters in two potato cultivars (Solanum tuberosum) contrasting in their salt tolerance (cv. Desiree; tolerant and Mozart; sensitive) grown at 0 and $60 \mathrm{mM} \mathrm{NaCl}$. Tonoplast-enriched vesicles were used to study the pump activity and protein levels of the $\mathrm{V}-\mathrm{H}^{+}$-ATPase and the $\mathrm{V}-\mathrm{H}^{+}-$PPase and the activity of the $\mathrm{Na}^{+} / \mathrm{H}^{+}$antiporter. Although salt stress reduced the $\mathrm{V}-\mathrm{H}^{+}$-ATPase and the $\mathrm{V}-\mathrm{H}^{+}$PPase activity in both cultivars, the decline in $\mathrm{H}^{+}$pump activity was more severe in the salt-sensitive cultivar Mozart. After salt treatment, protein amounts of the vacuolar $\mathrm{H}^{+}$ pumps decreased in Mozart but remained unchanged in the cultivar Desiree. Decreased protein amounts of the $\mathrm{V}-\mathrm{H}^{+}$-PPase found in Mozart may explain the reduced $\mathrm{V}-\mathrm{H}^{+}$PPase activity found for Mozart after salt stress. Under non-stress conditions, protein amounts of $\mathrm{V}-\mathrm{H}^{+}-$PPase were equal in both cultivars while the $\mathrm{V}-\mathrm{H}^{+}-\mathrm{PPase}$ activity was already twice as high and remained higher after salt treatment in the cultivar Desiree as compared to Mozart. This cultivar-dependent $\mathrm{V}-\mathrm{H}^{+}$-PPase activity may explain the higher salt tolerance of Desiree. Moreover, combined with reduced vacuolar $\mathrm{H}^{+}$pump activity, Mozart showed a lower $\mathrm{Na}^{+} / \mathrm{H}^{+}$exchange activity and the $K_{\mathrm{m}}$ for $\mathrm{Na}^{+}$is at least twofold lower in tonoplast vesicles from Desiree, what suggests that NHXs from Desiree have a higher affinity for $\mathrm{Na}^{+}$as compared to Mozart. From these results, we conclude that the higher capacity in combination with the higher affinity for $\mathrm{Na}^{+}$uptake can be an important factor to explain the differences in salt tolerance of these two potato cultivars.

\footnotetext{
Keywords: potato, vacuolar proton transport, $\mathrm{Na}^{+} / \mathrm{H}^{+}$exchange, $\mathrm{Na}^{+} / \mathrm{H}^{+}$antiporters, vacuolar $\mathrm{H}^{+}$-ATPase, vacuolar $\mathrm{H}^{+}$-PPase, tonoplast vesicles, salt tolerance
}

\section{INTRODUCTION}

Salinity is a serious threat to agricultural production of many crops. Potato is an important staple food in the human diet in many countries worldwide and the trend of potato production is toward more hectares in warmer and dryer climates (Levy and Veilleux, 2007). Soil salinization, often the result of poor irrigation practices, is one of the factors that limit potato production. Based 
on specific criteria, potato was found to be moderately sensitive to salinity and considering the importance of potato as a staple food, relatively few studies address the physiological, biochemical, and molecular responses that take place during salt stress in potato (Hmida-Sayari et al., 2005; Aghaei et al., 2009; Legay et al., 2009; Batelli et al., 2012; Jaarsma et al., 2013).

Current insights show that plants have developed many mechanisms to tolerate salt stress and three categories of adaptation can be distinguished, namely, osmotic tolerance, ion exclusion, and tissue tolerance (Munns and Tester, 2008; Roy et al., 2014). Roy et al. (2014) describe ion exclusion as an important mechanism to prevent $\mathrm{Na}^{+}$accumulation into shoots and leaves. However, if $\mathrm{Na}^{+}$travels into cells of leaves, efficient removal by compartmentalizing $\mathrm{Na}^{+}$in vacuoles prevents detrimental effects on cellular processes (Munns and Tester, 2008) such as premature senescence, already occurring over several days to weeks after salt stress (Roy et al., 2014). In a previous study, we found a strong premature senescence response in the leaves of the potato cultivar Mozart combined with relatively high $\mathrm{Na}^{+}$leaf accumulation, while the potato cultivar Desiree accumulated less $\mathrm{Na}^{+}$in leaves and did not show a senescence response after 7 days of salt treatment and we concluded that Desiree was salt tolerant and that Mozart was salt sensitive (Jaarsma et al., 2013). In the same study, we hypothesized that the vacuolar sequestration capacity of $\mathrm{Na}^{+}$in leaves of Mozart was lower than that of the more salt tolerant potato cultivar.

In vacuoles, $\mathrm{Na}^{+}$serves as an inorganic osmoticum to maintain turgor (Shabala and Mackay, 2011). $\mathrm{Na}^{+}$may enter vacuoles by the activity of $\mathrm{Na}^{+} / \mathrm{H}^{+}$antiporters energized by a proton motive force (PMF) established by vacuolar proton pumps. So far, there is still debate as to which gene or protein facilitates the $\mathrm{Na}^{+} / \mathrm{H}^{+}$antiport activity; however, many studies suggest a role for members of the NHX family (Munns and Tester, 2008; Rodríguez-Rosales et al., 2009; Pardo and Rubio, 2011), although AtNHX1 also catalyzes $\mathrm{K}^{+} / \mathrm{H}^{+}$antiport (Jiang et al., 2010) and SINHX2 from tomato (Solanum lycopersicum) was found to catalyze solely $\mathrm{K}^{+} / \mathrm{H}^{+}$antiport (RodríguezRosales et al., 2008). Hence, dual functions for NHX exchangers have been proposed (Yamaguchi et al., 2005; Jiang et al., 2010), and NHX isoforms also play significant roles in other cellular processes, such as membrane trafficking, $\mathrm{pH}$ - and ion homeostasis, stomatal regulation, cell turgor and growth and development (Bassil et al., 2011; Eckardt and Berkowitz, 2011; Barragan et al., 2012; Bassil and Blumwald, 2014; Reguera et al., 2015). Many studies showed improved salt tolerance and increased accumulation of $\mathrm{Na}^{+}$or $\mathrm{K}^{+}$when $N H X$ was expressed in a variety of plant species (Agarwal et al., 2012). However, expression of AtNHX1 in barley did not improve plant performance during saline conditions (Adem et al., 2015) and it was suggested before that efficient vacuolar $\mathrm{Na}^{+}$sequestration also depends on the permeability of slow- and fast-activating vacuolar channels (Bonales-Alatorre et al., 2013).

To transport ions into the vacuoles, an electrochemical $\mathrm{H}^{+}$ gradient across the tonoplast has to be established by $\mathrm{V}-\mathrm{H}^{+}$ATPases and/or $\mathrm{V}-\mathrm{H}^{+}$-PPases, using ATP and PPi as a substrate, respectively. Transcript levels of $V-H^{+}$-ATPase genes were only slightly induced in barley after salt stress (Fukuda et al., 2004) and in the woody plant Broussonetia papyrifera, transcript levels of several $\mathrm{V}-\mathrm{H}^{+}$-ATPase subunits increased upon salt treatment in root and leaf tissues (Zhang et al., 2012). Moreover, transgenic barley plants expressing the $\mathrm{V}-\mathrm{H}^{+}$-ATPase subunit $\mathrm{C}$ from Arabidopsis and Arabidopsis plants expressing subunits from wheat were found to be more salt tolerant (He et al., 2014; Adem et al., 2017). However, Arabidopsis mutant analysis showed that other roles for the $\mathrm{V}-\mathrm{H}^{+}$-ATPase are also found, like efficient nutrient storage (Krebs et al., 2010) and membrane trafficking, depending on their cellular localization (Schumacher and Krebs, 2010).

The wheat vacuolar proton-pumping pyrophosphatase $\left(\mathrm{H}^{+}\right.$PPase) genes (TaVP1 and TaVP2) showed induced expression in response to salinity (Wang et al., 2009) and were shown to have major roles in abiotic stress among other functions, such as maintaining cellular PPi homeostasis, heterotrophic growth, increased auxin transport, and sucrose transport from source to sink tissues (Schilling et al., 2017). In the context of salt tolerance, transgenic plants expressing $\mathrm{H}^{+}$-PPase accumulated more $\mathrm{Na}^{+}$in leaves or shoots and had higher $\mathrm{V}-\mathrm{H}^{+}$-PPase activity compared to wild-type plants (Gaxiola et al., 2001), while other transgenic plants expressing $\mathrm{H}^{+}$-PPase did not show higher $\mathrm{Na}^{+}$accumulation but may still compartmentalize more $\mathrm{Na}^{+}$in their vacuoles (Schilling et al., 2014). In addition, Queiros et al. (2009) provided evidence that a more efficient $\mathrm{Na}^{+}$sequestration mechanism improves salt tolerance in potato cells (Queiros et al., 2009). They adapted calli to $150 \mathrm{mM} \mathrm{NaCl}$ and the selected $\mathrm{NaCl}-$ tolerant calli lines showed higher ATP- and PPi-dependent $\mathrm{H}^{+}$ transport and higher $\mathrm{Na}^{+} / \mathrm{H}^{+}$antiport activity as compared to control cells. However, the vacuolar $\mathrm{Na}^{+}$sequestration system and its response to salinity stress in commercial potato cultivars have not been studied yet.

In this study, we compared Mozart and Desiree for the saltinduced changes in activity and expression of vacuolar $\mathrm{H}^{+}$pumps and vacuolar antiporters isolated from leaves. The main conclusion is that the $V_{\max }$ of both the $\mathrm{V}-\mathrm{H}^{+}$-ATPase and the $\mathrm{V}-\mathrm{H}^{+}$-PPase were reduced by salt in both Mozart and Desiree but the reduction was larger in Mozart as compared to Desiree. Furthermore, after salt treatment, the amount of both $\mathrm{V}-\mathrm{H}^{+}$ATPase and $\mathrm{V}-\mathrm{H}^{+}$-PPase proteins was reduced in Mozart but not in Desiree. In addition, the $\mathrm{Na}^{+} / \mathrm{H}^{+}$exchange system in the tolerant cultivar Desiree works more efficient as compared to the salt-sensitive cultivar Mozart.

\section{MATERIALS AND METHODS}

\section{Plant Material and Growth Conditions}

Two-week-old cuttings of two potato (Solanum tuberosum) cultivars Desiree and Mozart were planted in $4 \mathrm{~L}$ pots containing $1 / 2$ strength Hoagland solution and was refreshed every fourth day. Each pot contained four cuttings of the same cultivar held by a rockwool plug embedded in styrofoam in the lid of the pot. Plants were maintained in a growth chamber under a $16 / 8 \mathrm{~h}$ light/dark photoperiod, $24^{\circ} \mathrm{C} / 15^{\circ} \mathrm{C}$ day/night temperature and $70 \%$ relative humidity. After 3 weeks, plants were subjected to 
two treatments: $0 \mathrm{mM} \mathrm{NaCl}$ and $60 \mathrm{mM} \mathrm{NaCl}$. The salt treatment was applied two times, at the first and third day, respectively, and after 5 days the plants were harvested for further analysis. Both treatments were done with three or four independent biological replicates as indicated in the figures. The $0 \mathrm{mM} \mathrm{NaCl}$ treatment was normal $1 / 2$ strength Hoagland solution and the $60 \mathrm{mM} \mathrm{NaCl}$ treatment was $1 / 2$ strength Hoagland solution supplemented with $60 \mathrm{mM} \mathrm{NaCl}$. Each pot containing four cuttings was considered a biological replicate.

\section{Ion Analysis, Fresh/Dry Weight Ratio and Leaf Sap Osmolality}

At the end of each experiment, a small part of fresh leaves $(\sim 2 \mathrm{~g})$ was collected from 10 leaves. The leaves were collected from all parts of the plant to obtain a representative mix of old and young leaves in a similar way for all plants. Subsequently, the leaves were weighed to determine fresh weight (FW), before snap freezing in liquid nitrogen. To collect the leaf sap, each sample was ground for $30 \mathrm{~s}$ at room temperature and centrifuged at $15,000 \mathrm{~g}$ for $5 \mathrm{~min}$. Eight microliters of the supernatant was used to estimate the osmolality with an osmometer (Wescor 5500, Logan, UT, United States). Determination of $\mathrm{Na}^{+}$and $\mathrm{K}^{+}$was done as described before (Jaarsma et al., 2013). In short, fresh material was dried at $70^{\circ} \mathrm{C}$ for $24 \mathrm{~h}$ and $100 \mathrm{mg}$ dried plant material was extracted by $1 \mathrm{~h}$ boiling in $5 \mathrm{ml}$ MilliQ. The solution was filtered through $0.2 \mu \mathrm{m}$ filters (Whatman, England) and $\mathrm{Na}^{+}$ and $\mathrm{K}^{+}$concentrations in the filtrate were analyzed using highperformance liquid chromatography (HPLC, Shimadzu, Japan). The HPLC system was equipped with a $\varnothing 4.6 \mathrm{~mm} \times 125 \mathrm{~mm}$ Shodex IC YS-50 column (Showa Denko). As an eluent, $4.0 \mathrm{mM}$ methane sulfonic acid was used in HPLC-graded $\mathrm{H}_{2} \mathrm{O}$ (J.T. Baker, Netherlands) with a flow rate of $1 \mathrm{ml} / \mathrm{min}$. Final ion concentrations in the filtrate were calculated according to a calibration curve.

\section{Candidate Genes and Gene Expression Analysis}

Unigenes or genomic sequences with homology to SlVP1 and SlVP2 and SlNHX1-SlNHX4 were identified in potato by querying Potato databases ${ }^{1,2}$. Homology to tomato was determined at the nucleotide level and amino acid level. Potato unigenes from the SOL genomics database and the sequences from the Potato Genome Sequencing Consortium were designated StNHX1-StNHX4 according to SlNHXs and StVP1 and StVP2 according to SlVP1 and SlVP2. Unigenes were used to design primers with optimum settings of $40-60 \%$ GC content, $20 \mathrm{nt}$ in length, primer $\mathrm{Tm}$ of $60^{\circ} \mathrm{C}$ and an amplicon size of $100 \mathrm{bp}$. Designed primers were used in blast searches against the previously mentioned databases and only the primers that showed no significant matches other than the unigenes they were designed for were further tested. Subsequently, transcript levels were determined by RT-PCR and qPCR using cDNA from potato plants subjected to 0 and $60 \mathrm{mM} \mathrm{NaCl}$. Those genespecific primer pairs that resulted in a sharp band of the expected

${ }^{1}$ http://solgenomics.net

${ }^{2}$ http://solanaceae.plantbiology.msu.edu/pgsc_download.shtml amplicon size on agarose gels and showed a sharp peak after software analysis were chosen for qPCR analysis and are listed in Table 2.

RNA was isolated from leaves using the Nucleospin RNeasy plant mini kit (Qiagen, Leusden, Netherlands) and all samples were treated with DNase. Tissue was ground in liquid nitrogen using a mortar and pestle. Approximately $100 \mathrm{mg}$ of ground tissue was used for RNA isolation according to the manufacturer's instructions. cDNA was synthesized from 1 to $4 \mu \mathrm{g}$ RNA using Superscript II (Invitrogen) in a $20-\mu 1$ reaction volume containing $5 \mu \mathrm{M}$ oligo $\mathrm{dT}$ (T15) primer according to the manufacturer's protocol. qPCRs contained $100 \mathrm{ng}$ cDNA, 0.5 pmol of each primer (see candidate genes) and $2 \times$ Sybr Green PCR buffer (Bio-Rad, Hercules, CA, United States). The program for $\mathrm{qPCR}$ was set to $2 \mathrm{~min}$ at $50^{\circ} \mathrm{C}, 5 \mathrm{~min}$ at $95^{\circ} \mathrm{C}$, continued by 40 cycles of $95^{\circ} \mathrm{C}$ for $30 \mathrm{~s}$ and $30 \mathrm{~s}$ at $60^{\circ} \mathrm{C}$ and a melting curve analysis. qPCRs were performed in the CHROMO4 MJ research PTC200 (Bio-Rad, Hercules, CA, United States). Data were analyzed according to the qgene 96 program (Muller et al., 2002). The melting curves showed only one sharp peak at the expected melting temperature confirming that the amplification was gene-specific. The potato elongation factor ef1 $\alpha$ gene (AB061263, forward primer 5' $5^{\prime} 3^{\prime}$ ATTGGAAACGGATATGCTCCA, reverse primer $5^{\prime}-3^{\prime}$ TCCTTACCTGAACGCCTGTCA) was used as a reference gene since this gene was shown to be stable during salt stress (Nicot et al., 2005).

\section{SDS-PAGE and Immunoblotting}

Vacuolar membrane proteins $(10 \mu \mathrm{g})$ were separated on SDSPAGE $[10 \%(\mathrm{w} / \mathrm{v})$ polyacrylamide]. Prior to electrophoresis, samples were heated at $70^{\circ} \mathrm{C}$ for $10 \mathrm{~min}$, in $50 \mathrm{mM}$ Tris- $\mathrm{HCl}$, $\mathrm{pH} 6.8,2 \%(\mathrm{w} / \mathrm{v})$ sodium dodecyl sulphate (SDS), 5\% (v/v) $\beta$-mercaptoethanol, and $10 \%(\mathrm{v} / \mathrm{v})$ glycerol. Subsequently, the gels were stained with Coomassie Brilliant Blue $[0.125 \%(\mathrm{w} / \mathrm{v})$ in $50 \%(\mathrm{v} / \mathrm{v})$ methanol] $/ 10 \%(\mathrm{v} / \mathrm{v})$ acetic acid for $30 \mathrm{~min}$ and destained in 5\% (v/v) methanol/7.5\% (v/v) acetic acid overnight. Stained gels were scanned into greyscale and the optical density was determined using Scion Image. After scanning, proteins in the gels were electro-transferred onto a nitrocellulose membrane (Schleicher and Schuel, Dassel, Germany) in a transfer buffer containing $50 \mathrm{mM}$ Trizma, $380 \mathrm{mM}$ glycine, 0.02\% (w/v) SDS, and $20 \%(\mathrm{v} / \mathrm{v})$ methanol using electrophoresis. Subsequently, membranes were incubated for $1 \mathrm{~h}$ in blocking buffer containing $5 \%(\mathrm{w} / \mathrm{v})$ fat-free milk powder and $1 \%(\mathrm{w} / \mathrm{v})$ bovine serum albumin (BSA) in TRIS-buffered saline (TBS) supplemented with $0.1 \%(\mathrm{v} / \mathrm{v})$ Tween-20 (TBS-T). Membranes were then incubated overnight with primary antibodies diluted 1:2000 in blocking buffer. The primary antibodies were specific for subunit A of the V-ATPase and the V-PPase (AS09 467 and AS09-465, respectively, Agrisera, Sweden). After washing the membranes three times with TBS-T, the membranes were incubated with the secondary antibody for $45 \mathrm{~min}$. Following washing again, immune-detection was done using the ECL chemiluminescent detection kit (Amersham). Films were then scanned and the relative intensity of bands was determined by Scion Image. 


\section{Preparation of Tonoplast-Enriched Membrane Vesicles}

Tonoplast vesicles were isolated from leaves of 4-week-old potato plants by combining differential and sucrose gradient centrifugations as was shown to be effective for potato tissue (Queiros et al., 2009). Total leaf tissue, without stems or petioles (around $100 \mathrm{~g}$ ) was collected from 4-week-old potato plants (cv. Desiree and Mozart) grown on hydroponics and subjected to 0 and $60 \mathrm{mM} \mathrm{NaCl}$ for 1 week. The entire isolation procedure was performed at $4^{\circ} \mathrm{C}$ and at all intermediate steps the samples were kept on ice. Leaves of each cultivar and each treatment were ground separately by repeated transient pulsing in a blender containing $200 \mathrm{ml}$ ice-cold extraction buffer. The extraction buffer consisted of $250 \mathrm{mM}$ sucrose, $2 \mathrm{mM}$ EDTA (pH 8.0), $2 \mathrm{mM}$ dithiothreitol (DTT), $1 \mathrm{mM}$ phenylmethyl sulphonyl fluoride (PMSF), $70 \mathrm{mM}$ Tris- $\mathrm{HCl}$ (pH 8.0), $3 \mathrm{mM} \mathrm{MgCl} 2,100 \mathrm{mM}$ $\mathrm{KCl}, 0.1 \%(\mathrm{w} / \mathrm{v}) \mathrm{BSA}, 0.2 \%(\mathrm{w} / \mathrm{v})$ polyvinylpolypyrrolidone (PVPP), and $10 \mu \mathrm{M}$ cantharidin (a phosphatase inhibitor). The homogenate was filtered through four layers of miracloth and centrifuged at $10,000 \mathrm{~g}$ for $10 \mathrm{~min}$. The supernatants were centrifuged at $100,000 \mathrm{~g}$ for $1 \mathrm{~h}$. The microsomal pellet was resuspended in $10 \mathrm{ml}$ ice-cold resuspension buffer containing 15\% (v/v) glycerol, $1 \mathrm{mM}$ DTT, $1 \mathrm{mM}$ EDTA (pH 7.5), $1 \mathrm{mM}$ PMSF, $20 \mathrm{mM}$ Tris- $\mathrm{HCl}(\mathrm{pH}$ 7.5), and $10 \mu \mathrm{M}$ cantharidin. The diluted microsomal fraction was separated in tonoplast membrane-enriched vesicles and plasma membrane-enriched vesicles by $3 \mathrm{~h}$ centrifugation at 80,000 $\mathrm{g}$ (Beckman SW 28 rotor) on a $0-32-46 \%(\mathrm{w} / \mathrm{v})$ sucrose step gradient. Next to sucrose, the step gradient contained $20 \mathrm{mM}$ Tris- $\mathrm{HCl}(\mathrm{pH} 7.5)$, $1 \mathrm{mM}$ EDTA (pH 7.5), $1 \mathrm{mM}$ DTT, $1 \mathrm{mM}$ PMSF, and $10 \mu \mathrm{M}$ cantharidin. Subsequently, the tonoplast-enriched vesicles were collected at the $0-32 \%$ sucrose interface and approximately four times diluted in resuspension buffer and centrifuged at $100,000 \mathrm{~g}$ for $30 \mathrm{~min}$. The pellets were resuspended in $1 \mathrm{ml}$ resuspension buffer. The tonoplast vesicles were homogenized by gently swirling before aliquoting. Aliquots were snap-frozen in liquid nitrogen and stored at $-80^{\circ} \mathrm{C}$ until further use. Before freezing, the protein concentration was measured by means of a Bradford assay (Bio-Rad), using BSA as a protein standard.

\section{Fluorescence Quench Assays}

Tonoplast vesicles were used in proton transport assays. $\mathrm{H}^{+}$transport across the tonoplast vesicles was energized by the addition of ATP or PPi in different concentrations as indicated in the "Results" section. Prior to measuring the substratedependent proton pump activity, the vesicles were characterized for their purity as contamination with vesicles derived from the plasma membrane is possible. This was done by adding $1 \mathrm{mM}$ ATP to energize ATPases (both the V-ATPases and the PMATPases if present) in the presence of several concentrations of bafilomycin. Bafilomycin is a specific inhibitor of the activity of the $\mathrm{V}-\mathrm{H}^{+}$-ATPase, and does not affect the activity of the P-type $\mathrm{H}^{+}$-ATPase found in plasma membranes or any other $\mathrm{H}^{+}$-ATPase. Therefore, a strong inhibition of ATP-dependent $\mathrm{H}^{+}$pumping activity by bafilomycin is an indication that
TABLE 1 | $\mathrm{Na}^{+}$and $\mathrm{K}^{+}$concentrations in the leaves of the potato cultivars Desiree and Mozart grown in the absence and presence of $60 \mathrm{mM} \mathrm{NaCl}$.

\begin{tabular}{llll}
\hline Cultivar & Treatment & {$\left[\mathbf{N a}^{+}\right] \mathbf{~} \mathbf{~ g ~ g ~}^{-\mathbf{1}} \mathbf{D W}$} & $\mathbf{[ K}^{+} \mathbf{]} \mathbf{~ m g ~ g}^{-\mathbf{1}} \mathbf{~ D W}$ \\
\hline Desiree & $0 \mathrm{mM} \mathrm{NaCl}$ & $2.2 \pm 0.3(\mathrm{a})$ & $34.6 \pm 2.9(\mathrm{a})$ \\
& $60 \mathrm{mM} \mathrm{NaCl}$ & $17.8 \pm 1(\mathrm{~b})$ & $31.4 \pm 3.3(\mathrm{a})$ \\
Mozart & $0 \mathrm{mM} \mathrm{NaCl}$ & $2.2 \pm 0.2(\mathrm{a})$ & $43.7 \pm 4.4(\mathrm{a})$ \\
& $60 \mathrm{mM} \mathrm{NaCl}$ & $24.2 \pm 1.8(\mathrm{c})$ & $25.4 \pm 2.7(\mathrm{~b})$ \\
\hline
\end{tabular}

Results are the mean \pm SEM for four biological replicates. Different letters indicate a statistically significant treatment effect (one-way ANOVA; $P<0.05$ ). A statistically significant treatment $\times$ cultivar interaction effect was found for both $\mathrm{Na}^{+}$and $\mathrm{K}^{+}$ concentrations (two-way ANOVA; $P<0.05$ ). DW, plant dry weight.

isolated vesicles are enriched in tonoplast membranes. The initial percentage rate of the fluorescence change of $2 \mu \mathrm{M} 9-$ amino-6-chloro-2-methoxyacridine (ACMA; $\Delta \% \mathrm{~F} \mathrm{~min}^{-1} \mathrm{mg}^{-1}$ protein) was determined. The reaction medium contained $10 \mathrm{mM}$ Mops-TRIS (pH 7.0), $5 \mathrm{mM} \mathrm{MgCl} 2$ and $100 \mathrm{mM} \mathrm{KCl}$ and $20 \mu \mathrm{g}$ of tonoplast vesicles and fluorescence quenching was monitored using a spectrophotometer (Hitachi) at excitation and emission wavelengths of 415 and $485 \mathrm{~nm}$, respectively, as described by Queiros et al. (2009). A pH gradient was established by activation of the $\mathrm{V}-\mathrm{H}^{+}$-PPase with $0.5 \mathrm{mM}$ PPi in reaction media as described above. After the fluorescence had reached a steady state, the reaction medium was supplemented with different concentrations of $\mathrm{Na}_{2} \mathrm{SO}_{4}$ as indicated in the "Results" section to dissipate the $\mathrm{pH}$ gradient. The initial slope of the recovery of fluorescence quench represented the activity of $\mathrm{Na}^{+} / \mathrm{H}^{+}$antiport activity, expressed as $\Delta \% \mathrm{~F} \mathrm{~min}^{-1} \mathrm{mg}$ protein $^{-1}$.

\section{Statistics}

All data reported in this work were obtained from three or four biologically independent pot experiments as indicated in the figures. Each pot experiment was arranged in a randomized design with two salt treatments. Data were analyzed with one-way ANOVA and two-way ANOVA with a multiple comparison test (Tukey's test; SPSS) or Student's $t$-test as indicated in the figures. Differences between treatments and/or cultivars were considered significant when $P<0.05$.

\section{RESULTS}

\section{$\mathrm{Na}^{+}$and $\mathrm{K}^{+}$Concentrations, Water Status and Osmolality of the Leaves}

Table 1 shows $\mathrm{Na}^{+}$and $\mathrm{K}^{+}$concentrations accumulated in leaf tissue after salt treatment. Mozart accumulated over 30\% more $\mathrm{Na}^{+}$in leaf tissue compared to Desiree. The $\mathrm{K}^{+}$concentrations in leaves of Desiree grown at $60 \mathrm{mM} \mathrm{NaCl}$ was the same as that of the control leaves, whereas leaves of Mozart grown at $60 \mathrm{mM} \mathrm{NaCl}$ showed a significant reduction in $\mathrm{K}^{+}$concentrations by more than $40 \%$. Subsequently, we determined the fresh weight/dry weight (FW/DW) ratio of leaves and the osmolality of the leaf sap (Figure 1) as described in the "Materials and Methods" section. Leaves collected from salt-treated plants of Mozart showed a significantly lower FW/DW ratio as compared to 
TABLE 2 | Homologs of a selection of genes involved in vacuolar ion transport were identified in potato by querying a database containing potato SGN unigenes (see footnote 1) and genomic sequences (see footnote 2) using coding sequences from tomato in blast searches.

\begin{tabular}{|c|c|c|c|c|}
\hline Gene & $\begin{array}{l}\text { Annotation/Gene } \\
\text { accession }\end{array}$ & $\%$ Homology to & Primer $5^{\prime} \rightarrow 3^{\prime}$ & Amplicon size \\
\hline SIVP1 & AB300442 & $97 \%$ to SGN-U268918 & $\begin{array}{l}\text { Fw. CTCTTCCCCCGTATITCACA } \\
\text { Rv. CCTCCACAGCCTAACACCAT }\end{array}$ & 100 bp \\
\hline SIVP2 & LES278019 & $97 \%$ to SGN-U269308 & $\begin{array}{l}\text { Fw. GGTCCTATCAGTGACAATGCTG } \\
\text { Rv. AACAGAGCCAGGGACACAAG }\end{array}$ & $161 \mathrm{bp}$ \\
\hline SINHX1 & AJ306630 & $97 \%$ to See text & $\begin{array}{l}\text { Fw. TGTTGATCCCTITCGACCAT } \\
\text { Rv. CCAAATAGGGGTCGCATAAA }\end{array}$ & $111 \mathrm{bp}$ \\
\hline SINHX2 & AJ306631 & $98 \%$ to SGN-U296226 & $\begin{array}{l}\text { Fw. TTGGCACAGACGTGAACCTA } \\
\text { Rv. GTGGCTTCTGACCAGTGACA }\end{array}$ & 107 bp \\
\hline SINHX3 & AM261867 & $98 \%$ to SGN-U273140 & $\begin{array}{l}\text { Fw. AGAAGTCTCCGGAGGAGAGG } \\
\text { Rv. GCGTTGGCACGTAACTGAGTA }\end{array}$ & 139 bp \\
\hline SINHX4 & AM261867 & $98 \%$ to SGN-U275721 & $\begin{array}{l}\text { Fw. TCCTAGGCAGTCGAGAGGAC } \\
\text { Rv. TGGTGCGGTAAGTAGCATCC }\end{array}$ & $89 \mathrm{bp}$ \\
\hline
\end{tabular}

leaves collected from salt-treated plants of Desiree and the control plants (Figure 1A). The lower water uptake observed in Mozart leaves treated with $\mathrm{NaCl}$, combined with the higher $\mathrm{Na}^{+}$ concentrations in the leaves resulted in a higher osmolality of leaf sap (Figure 1B). Salt treatment increased the leaf sap osmolality of both salt-treated cultivars significantly, but the osmolality was about 25\% higher in Mozart after salt treatment as compared to that of Desiree (Figure 1B). Next, we addressed the question whether the observed differences in $\mathrm{Na}^{+}$and $\mathrm{K}^{+}$accumulation relate to differences in the activity of vacuolar transporters.

\section{Proton Pump Activity in Isolated Vesicles Is Bafilomycin Sensitive}

Figure 2A shows that increasing concentrations of bafilomycin recovered the ATP-driven fluorescence quench. With the initial fluorescence quenches measured without bafilomycin set to $100 \%$, it was found that the $\mathrm{EC}_{50}$ of the bafilomycin concentration was as low as $0.2 \mathrm{nM}$ for ATP-dependent pump activity and with $1.5 \mathrm{nM}$ bafilomycin in the reaction medium the ATP-dependent pump activity was inhibited by around 97\% (Figure 2B). These results indicate that the isolated membrane vesicles are highly enriched in vacuolar membranes.

\section{Effect of Salt Treatment on V-H ${ }^{+}-$PPase- and $\mathbf{V}-\mathrm{H}^{+}$-ATPase Activity}

The substrate-induced quench appeared almost instantaneously upon energization and after signal stabilization, the addition of $\mathrm{NH}_{4} \mathrm{Cl}$ rapidly dissipated the $\mathrm{pH}$ gradient (Figure $3 \mathrm{~A}$ for $\mathrm{PPi}$ and Figure 4A for ATP). Measurements were done with vesicles derived from both cultivars treated with 0 and $60 \mathrm{mM} \mathrm{NaCl}$ and the initial rates of proton pumping were plotted against increasing concentrations of PPi and ATP (Figures 3B, 4B). The curves showed Michaelis-Menten-like kinetics and both kinetic parameters, $K_{\mathrm{m}}$ and $V_{\max }$, were calculated and averaged, where $K_{\mathrm{m}}$ represents the affinity for the substrate and $V_{\max }$ represents the maximum pump activity.

The $K_{\mathrm{m}}$ of $\mathrm{PP}_{\mathrm{i}}$-dependent proton pumping was similar for both cultivars and was not modulated by salt (Figure 3 ). The $\mathrm{V}-\mathrm{H}^{+}$-PPase activity in vesicles obtained from Desiree was significantly higher, in control conditions (twofold) and after salt treatment (threefold), compared to the $\mathrm{V}-\mathrm{H}^{+}$-PPase activity from Mozart (Figure 3). Furthermore, salt treatment had a larger negative effect on the $\mathrm{V}-\mathrm{H}^{+}$-PPase activity in Mozart $(-75 \%)$ as compared to Desiree ( $-55 \%$; Figure 3).

The $\mathrm{V}-\mathrm{H}^{+}$-ATPase activity in control plants of Mozart showed a significant lower $K_{\mathrm{m}}$ value $(0.028 \mathrm{mM})$ compared to control plants from Desiree $(0.081 \mathrm{mM}$; Figure 4). After salt treatment, the $K_{\mathrm{m}}$ value significantly decreased for Desiree $(\sim 70 \%)$ but not for Mozart (Figure 4). The $\mathrm{V}-\mathrm{H}^{+}$-ATPase activity was significantly lower in Mozart plants after salt treatment (-80\%) while the $\mathrm{V}-\mathrm{H}^{+}$-ATPase activity in Desiree was only $30 \%$ lower after salt treatment (Figure 4). The $\mathrm{V}-\mathrm{H}^{+}$-ATPase activity of salttreated Desiree plants was similar to that of control plants of Mozart (Figure 4).

\section{Immunological Detection of the V-ATPase A-Subunit and the V-PPase in Response to Salt}

Western blotting shows a single band at $75 \mathrm{kDa}$ band for the $\mathrm{V}-\mathrm{H}^{+}$-PPase (Figures $\mathbf{5 C}-\mathbf{F}$ ) and a $69-\mathrm{kDa}$ band for the $\mathrm{V}-\mathrm{H}^{+}$-ATPase subunit A (Figures 5G-J). Densitometric analysis of the relative abundance of the $\mathrm{V}-\mathrm{H}^{+}-\mathrm{PPase}$ showed that salt treatment had no effect on the $\mathrm{V}-\mathrm{H}^{+}$PPase amount in Desiree (Figure 5C), whereas in Mozart the amount of $\mathrm{V}-\mathrm{H}^{+}$-PPase significantly decreased more than $30 \%$ (Figure 5D). These changes in protein amount only partly explain the observed salt-induced reductions in the $\mathrm{V}-\mathrm{H}^{+}$-PPase activity (Figure 3B), with a twofold and threefold reduction in Desiree and Mozart, respectively. Furthermore, the $\mathrm{V}-\mathrm{H}^{+}$-PPase protein amounts in control plants of Desiree and Mozart were equal (Figure 5E) and did not correlate with the differences in $\mathrm{V}-\mathrm{H}^{+}$-PPase activity in control plants (45\% lower in Mozart as compared to Desiree; Figure 3B).

Analysis of the $\mathrm{V}-\mathrm{H}^{+}$-ATPase Western blots showed a pattern similar to that of the $\mathrm{V}-\mathrm{H}^{+}$-PPase: no salt-induced change in Desiree and a significant $40 \%$ reduction of the $\mathrm{V}-\mathrm{H}^{+}$-ATPase in Mozart (Figures 5G,H). 

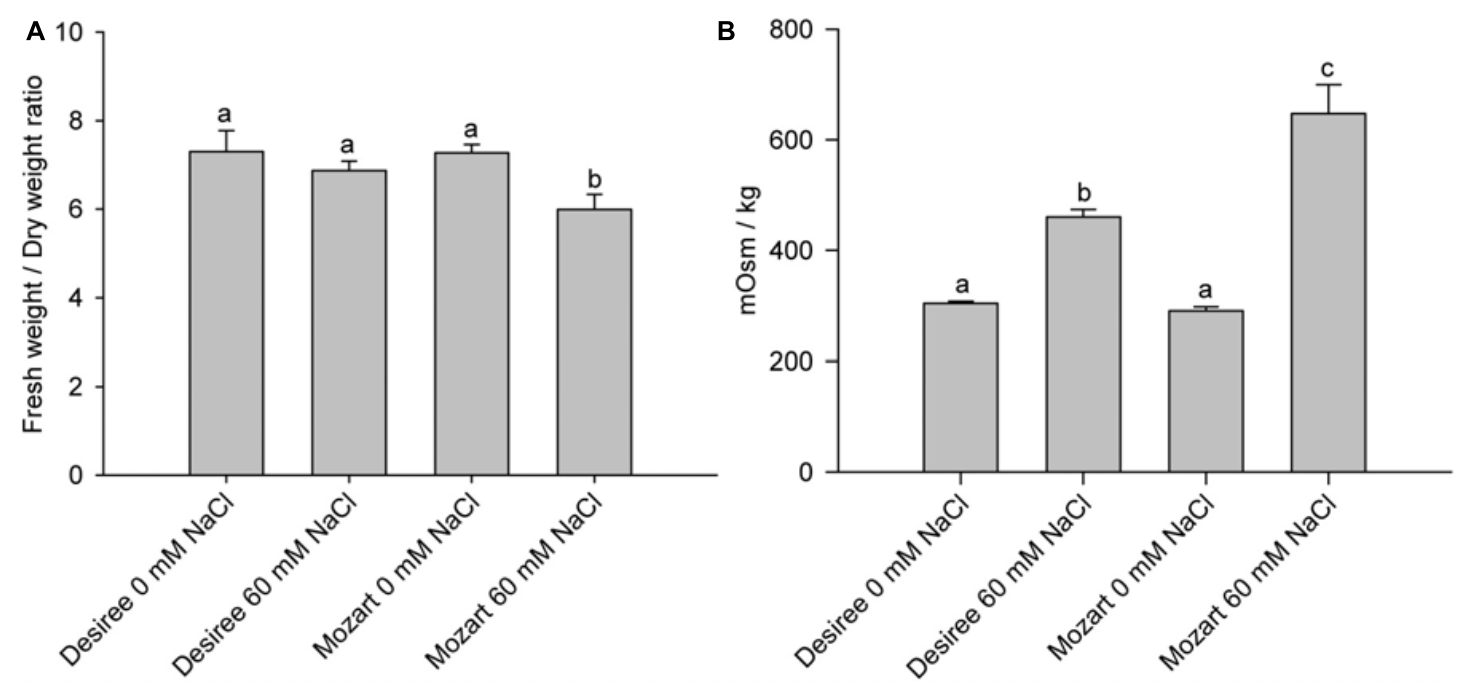

FIGURE 1 | Leaf parameters of Desiree and Mozart grown without and with $60 \mathrm{mM} \mathrm{NaCl}$. (A) The fresh weight/dry weight ratio for each treatment and cultivar. (B) The osmolality (mOsm kg ${ }^{-1}$ ) of the leaf sap of each treatment and cultivar. The osmolality of the leaf sap was measured with an osmometer (Wescor 5500 , Wescor, Logan, UT, United States). Results shown are the average of three independent experiments \pm SEM. Different letters indicate a statistically significant treatment effect (one-way ANOVA; $P<0.05$ ). A two-way ANOVA showed a treatment $\times$ cultivar interaction effect for the fresh weight/dry weight ratio and the osmolality $(P<0.05)$.
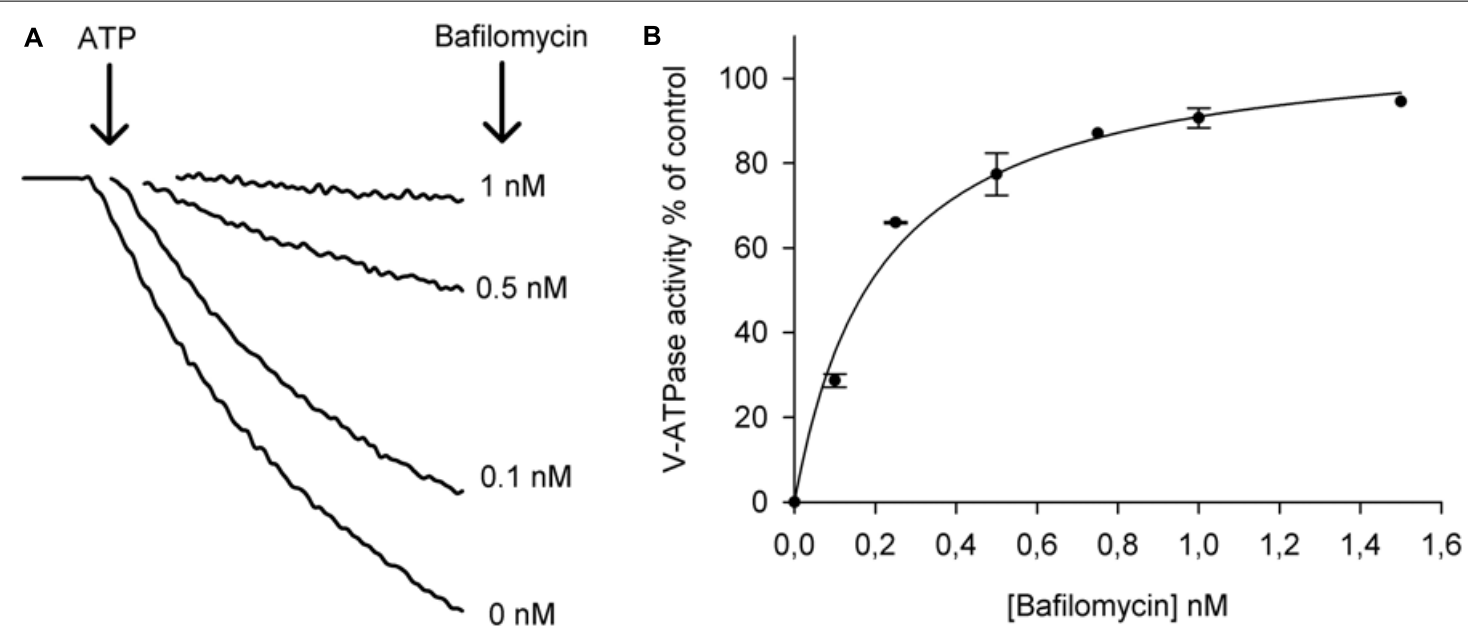

FIGURE 2 | Activation of the $\mathrm{V}-\mathrm{H}^{+}$-ATPase in tonoplast vesicles isolated from leaves and the sensitivity for the inhibitor bafilomycin. (A) ATP-driven fluorescence quench of ACMA in the absence of bafilomycin $(0 \mathrm{nM})$ and in the presence of $0.1,0.5$, and $1 \mathrm{nM}$ bafilomycin. The reactions were started by the addition of $1 \mathrm{mM}$ Mg ATP to the assay medium containing $20 \mu \mathrm{g}$ protein of tonoplast vesicles. (B) Dose response curve of the inhibition of V-H ${ }^{+}$-ATPase activity by bafilomycin. The curve was fitted to a Michaelis-Menten equation with the aid of SigmaPlot software package $(n=3 \pm$ SEM).

\section{Vacuolar $\mathrm{Na}^{+} / \mathrm{H}^{+}$Antiport Activity and Response to Salt}

Figure 6A shows the effect of different concentrations of $\mathrm{Na}^{+}$on the dissipation of a pre-established $\mathrm{pH}$ gradient in tonoplast vesicles from control- and salt-treated plants of both cultivars. The ACMA fluorescence recovered with the addition of increasing concentrations of $\mathrm{Na}^{+}$and followed saturation kinetics. Kinetic analysis of the saturation curves revealed that the salt treatment hardly affected the $V_{\max }$ of $\mathrm{Na}^{+}$transport in vesicles derived from either Desiree or Mozart (Figure 6B).
However, the $V_{\max }$ for $\mathrm{Na}^{+} / \mathrm{H}^{+}$-antiport was significantly higher (twofold) in Desiree as compared to the $V_{\max }$ from Mozart. Furthermore, the $\mathrm{Na}^{+} / \mathrm{H}^{+}$antiport system of Desiree showed a twofold to threefold higher affinity for $\mathrm{Na}^{+}$than the $\mathrm{Na}^{+} / \mathrm{H}^{+}$ antiport system of Mozart (Figure 6B).

\section{Gene Expression of Vacuolar Ion Transporters}

Three potato unigenes were found for three $V$-PPases corresponding to two type I and one type II $\mathrm{V}-\mathrm{H}^{+}$-PPases as 

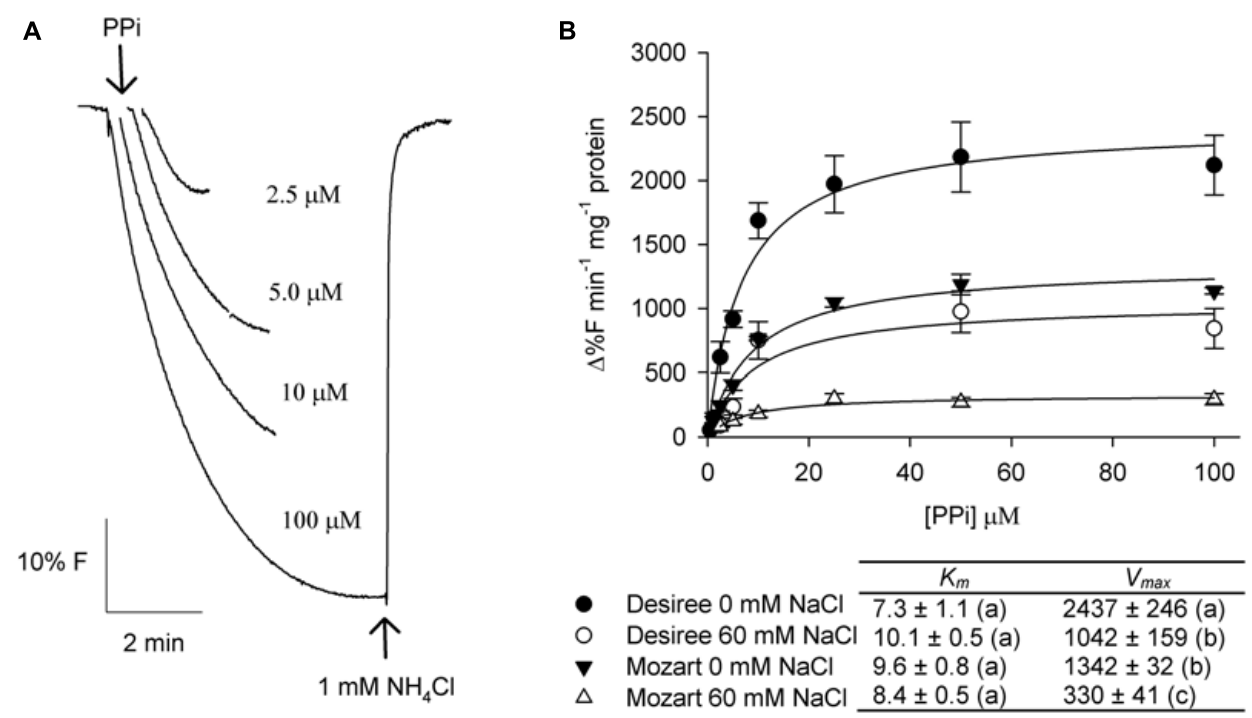

FIGURE 3 | Effect of salt stress on the PPi-dependent proton transport activity in tonoplast vesicles isolated from potato leaves. (A) Representative traces of proton pump activity in tonoplast vesicles isolated from leaves of the cultivar Desiree. The $\mathrm{V}-\mathrm{H}^{+}-\mathrm{PPase}$ was activated by the addition of increasing concentrations of PPi to the assay medium containing $20 \mu \mathrm{g}$ protein of membrane vesicles. After equilibration $1 \mathrm{mM} \mathrm{NH}_{4} \mathrm{Cl}$ was added to release the quench. (B) Dose response curves of the initial rates of proton pump activity of the $\mathrm{V}-\mathrm{H}^{+}-\mathrm{PPase}$ in dependence of the substrate PPi concentration for both cultivars treated with and without $60 \mathrm{mM} \mathrm{NaCl}$. The curves were fitted with the Michaelis-Menten equation with the aid of SigmaPlot software package. The average $K_{m}$ and $V_{\text {max }}$ values as shown in the table were calculated from the fit of each independent experiment $(n=3 \pm \mathrm{SEM}$ ). Different letters indicate a statistically significant treatment effect (one-way ANOVA; $P<0.05)$. A two-way ANOVA showed a treatment $\times$ cultivar interaction effect for $V_{\max }(P<0.05)$.
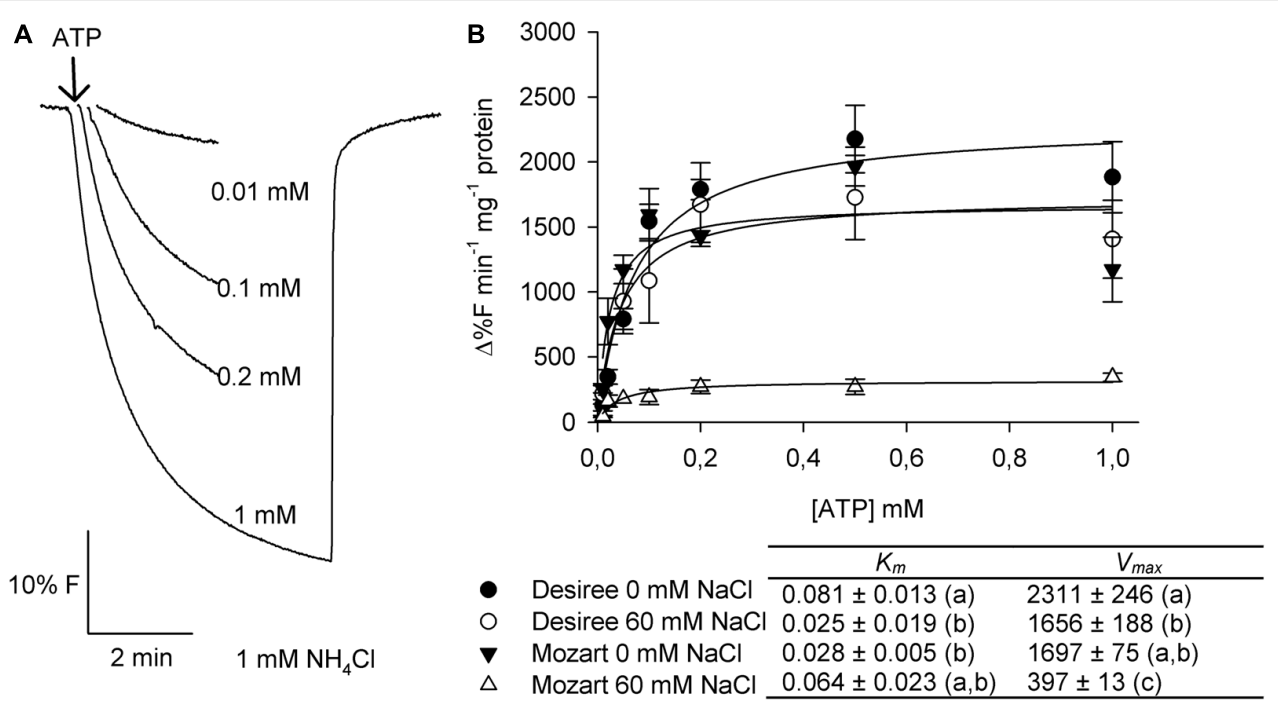

FIGURE 4 | Effect of salt stress on the ATP-dependent proton transport activity in tonoplast vesicles isolated from potato leaves. (A) Representative traces of proton pump activity in tonoplast vesicles isolated from leaves of the cultivar Desiree. The $\mathrm{V}-\mathrm{H}^{+}$-ATPase was activated by the addition of increasing concentrations of ATP

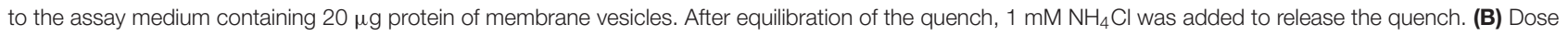
response curves of the initial rates of proton pump activity of the $\mathrm{V}-\mathrm{H}^{+}$-ATPase in dependence of the substrate ATP concentration for both cultivars treated with and without $60 \mathrm{mM} \mathrm{NaCl}$. The curves were fitted with the Michaelis-Menten equation with the aid of SigmaPlot software package. The average $K_{\mathrm{m}}$ and $V_{\text {max }}$ values as shown in the table were calculated from the fit of each independent experiment $(n=3 \pm \mathrm{SEM})$. Different letters indicate a statistically significant treatment effect (one-way ANOVA; $P<0.05)$. A two-way ANOVA showed a treatment $\times$ cultivar interaction effect for both $K_{\mathrm{m}}$ and $V_{\mathrm{max}}(P<0.05)$.

previously described for tomato (Mohammed et al., 2012). Type $\mathrm{I} \mathrm{V}-\mathrm{H}^{+}$-PPases depend on cytosolic $\mathrm{K}^{+}$for their activity and are localized in the tonoplast whereas type II $\mathrm{V}-\mathrm{H}^{+}$-PPases are $\mathrm{K}^{+}$insensitive and directed to the Golgi apparatus (Maeshima,
2000). Unigenes of the two type I V-H ${ }^{+}$-PPases (SlVP1 and SlVP2) were used for expression analysis (Table 2). A homology search of four SlNHX isoforms from tomato (Gálvez et al., 2012) on the public database SOL Genomics (see footnote 1) resulted in 


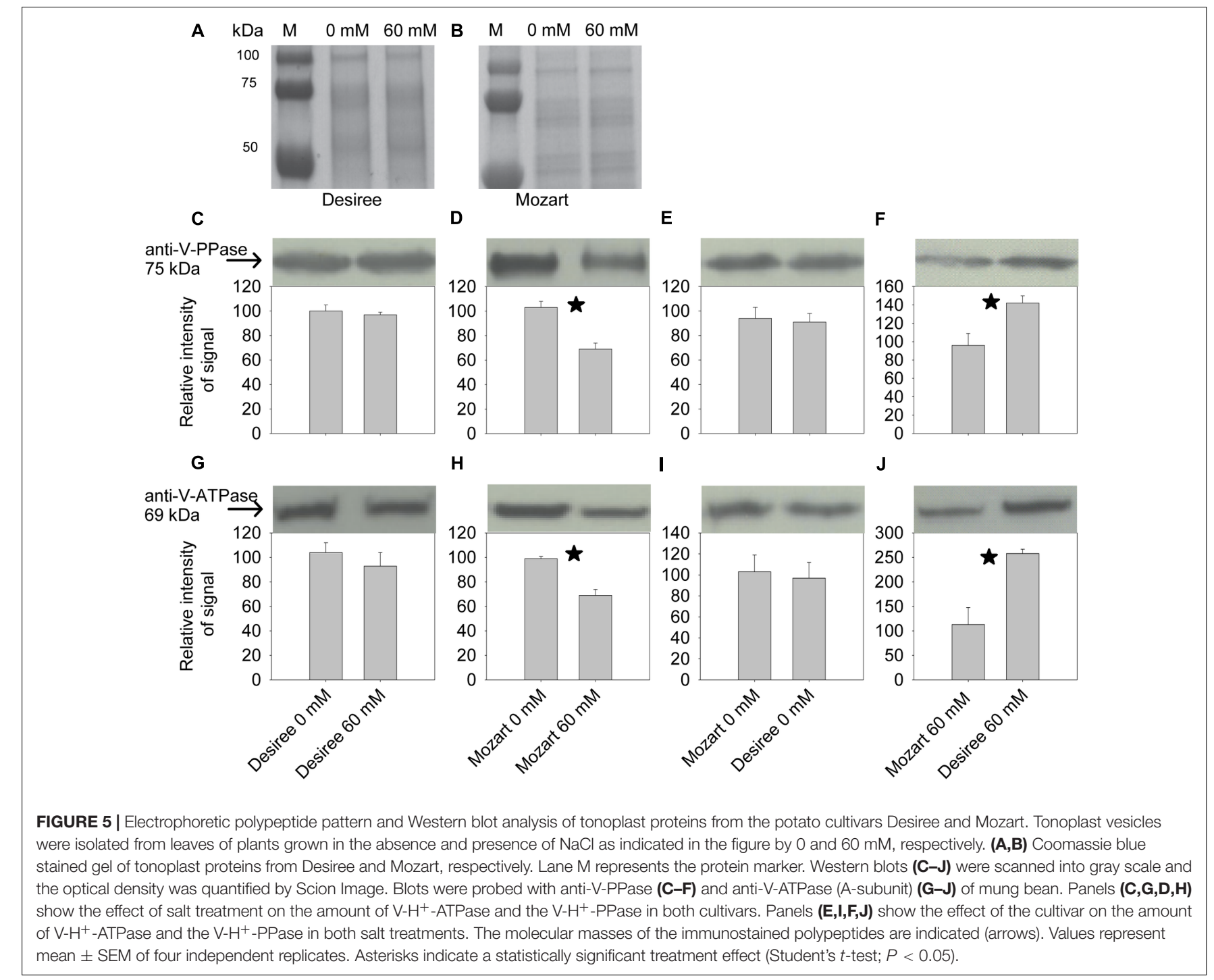

three unigenes with homology to SINHX2, SINHX3, and SINHX4, respectively. A homolog of SINHX1 was absent on the SOL Genomics network but the genomic sequence was found in the public database of the Potato Genome Sequencing Consortium ${ }^{3}$ (Database file: PGSC_DM_v4.03) and primers were designed in putative exons (Table 2). Within the four NHX isoforms tested, the expression level of StNHX1 was overall low, those of StNHX4 were highest and expression levels of StNHX2 and StNHX3 were intermediate (Figure 7 and Supplementary Data Sheet 1). Salt treatment induced StNHX2 transcripts in Mozart and induced StNHX3 transcripts in Desiree and no effect of salt was found on StNHX4 transcripts (Figure 7).

Expression of StVP1 remained unchanged in salt-treated plants of Desiree, whereas in Mozart the expression level in control plants was twofold higher as in Desiree, but salt stress reduced the expression twofold (Figure 7). Expression of StVP2 was lower than that of StVP1 and a small significant increase

${ }^{3}$ http://solanaceae.plantbiology.msu.edu/pgsc_download.shtml in expression was observed in both cultivars upon salt stress (Figure 7).

\section{DISCUSSION}

\section{General}

The study presented here confirmed our previous results that Mozart accumulates more $\mathrm{Na}^{+}$in leaves (35\% more) as compared to salt-treated Desiree plants (Table 1) (Jaarsma et al., 2013). If Mozart was a salt includer with an efficient vacuolar $\mathrm{Na}^{+}$ sequestration mechanism, then it might profit from the higher $\mathrm{Na}^{+}$levels by using $\mathrm{Na}^{+}$as osmoticum (Shabala and Mackay, 2011). However, the lower FW/DW ratio of leaves of salttreated Mozart plants (Figure 1A) indicates that these plants have difficulties to take up water in their leaves resulting in higher leaf sap osmolality (Figure 1B). In view of the premature senescence and the sensitivity of leaf growth of Mozart to salt stress found in our previous study, we hypothesized before that the vacuolar 

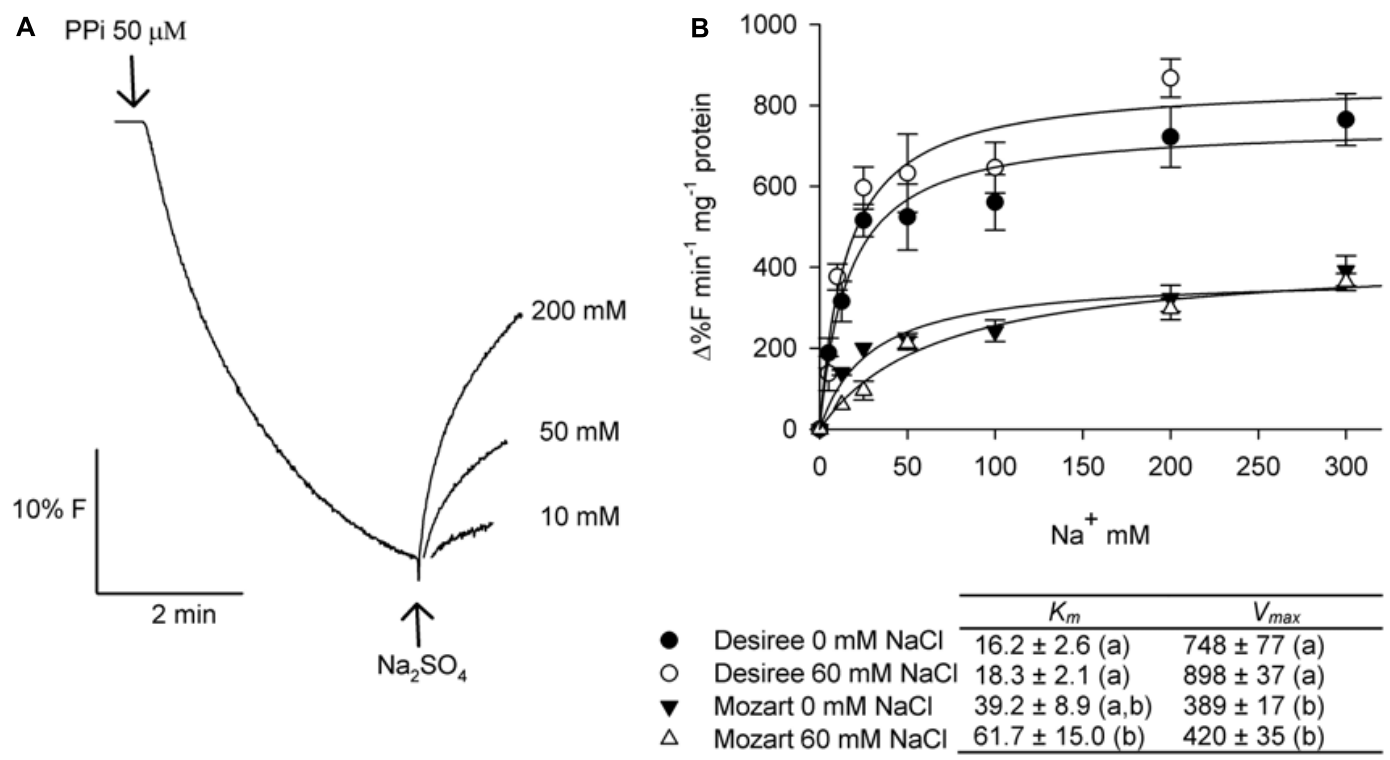

FIGURE 6 | Effect of salt stress on $\mathrm{Na}^{+} / \mathrm{H}^{+}$antiport activity in tonoplast vesicles isolated from potato leaves. (A) Representative curve showing the dissipation of the PPi-generated fluorescence quench $\left(\mathrm{H}^{+}\right.$gradient) with the addition of increasing concentrations of $\mathrm{Na}^{+}$to tonoplast vesicles from the cultivar Desiree. (B) Dose response curves where the initial rates of $\mathrm{Na}^{+}$-induced proton gradient dissipation are plotted against the $\mathrm{Na}^{+} \mathrm{concentration}\left(2.5-150 \mathrm{mM} \mathrm{Na}_{2} \mathrm{SO}_{4}\right)$. Tonoplast vesicles were isolated from leaves of Desiree and Mozart plants grown in the absence and the presence of $60 \mathrm{mM} \mathrm{NaCl}$. Experimental data of each individual curve ( $n=3 \pm$ SEM) were fitted to the Michaelis-Menten equation with the aid of SigmaPlot software package and the average $K_{m}$ and $V_{\text {max }}$ values are shown in the table. Different letters indicate a statistically significant treatment effect (one-way ANOVA; $P<0.05$ ). A statistically significant treatment $\times$ cultivar interaction effect was found for both $K_{m}$ and $V_{\max }$ (two-way ANOVA; $P<0.05$ ).

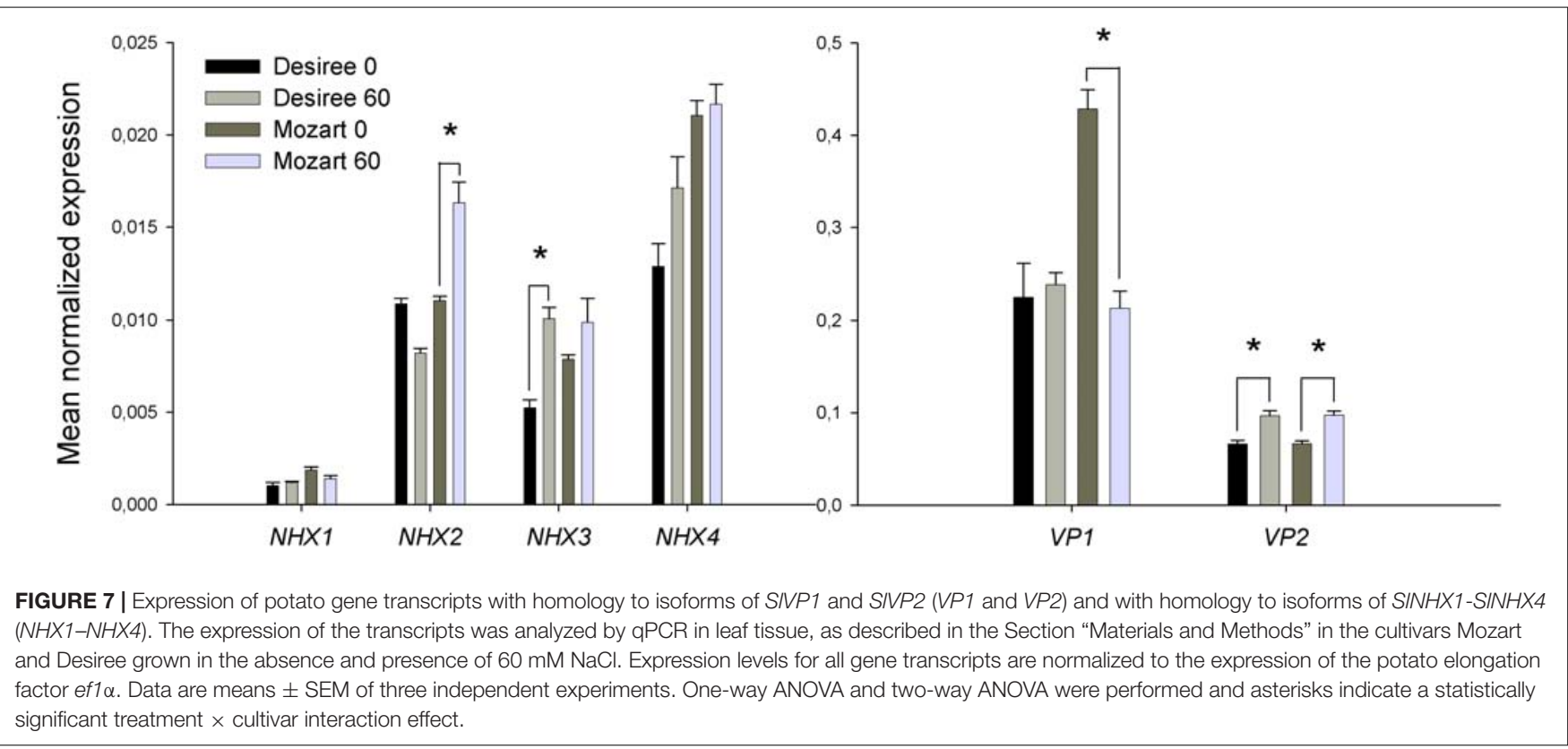

sequestration mechanism operates far from optimal in Mozart (Jaarsma et al., 2013).

\section{Generation of the PMF Is Modulated by Salt and Is Cultivar-Dependent in Potato}

In this study, we used ACMA fluorescence quench assays and the $\mathrm{V}-\mathrm{H}^{+}$ATPase and the $\mathrm{V}-\mathrm{H}^{+}$-PPase generated and maintained the electrochemical gradient across the vacuolar membrane in both cultivars, as was found before for potato tissue (Queiros et al., 2009). In both cultivars, the $\mathrm{V}-\mathrm{H}^{+}$-PPase activity showed a major salt-induced reduction, but the reduction was larger in Mozart than in Desiree (Figure 3). Furthermore, the $\mathrm{V}-\mathrm{H}^{+}$-PPase activity in control plants of Desiree was already higher than the $\mathrm{V}-\mathrm{H}^{+}$PPase activity in control plants of Mozart (Figure 3). From these 
results, we conclude that the $\mathrm{V}-\mathrm{H}^{+}$-PPase is salt sensitive in both cultivars and that $\mathrm{V}-\mathrm{H}^{+}$-PPase activity is cultivar dependent and higher in Desiree.

The $\mathrm{V}-\mathrm{H}^{+}$-ATPase activity showed a salt-induced reduction of $\sim 80 \%$ in Mozart, whereas salt treatment reduced the $\mathrm{V}-\mathrm{H}^{+}$ATPase activity in Desiree by $\sim 30 \%$ (Figure 4). Overall, salt considerably reduced the activity of both proton pumps in vesicles isolated from Mozart as compared to those of Desiree. As a consequence, Desiree generates a higher PMF across the tonoplast that can be used to energize the vacuolar transport of $\mathrm{Na}^{+}$.

\section{V-H ${ }^{+}$-PPase and V-H ${ }^{+}$-ATPase Protein Amounts Show a Salt-Induced Decrease in Mozart}

The Western blots showed a salt-induced reduction in the amount of $\mathrm{V}-\mathrm{H}^{+}$-PPase proteins in salt-treated plants of the cultivar Mozart ( $-40 \%$; Figure 5) and this correlated reasonably well with the salt-reduced pump activity observed in Mozart. The transcript levels of the StVP1 gene were twofold lower in salttreated Mozart plants as compared to control plants (Figure 7). These lower transcripts correlated to the salt-induced reduction in the protein amounts found for $\mathrm{V}-\mathrm{H}^{+}$-PPase. So, for Mozart, the salt-reduced pump activity may be a result of the reduction in gene expression and total protein amount. However, there was no reduction in the amounts of the $\mathrm{V}-\mathrm{H}^{+}$-PPase protein in Desiree after salt treatment (Figure 5). Hence, the correlation found for Mozart between lower $\mathrm{V}-\mathrm{H}^{+}$-PPase protein amounts and lower $\mathrm{V}-\mathrm{H}^{+}$-PPase activity does not hold for Desiree.

Furthermore, a reduction was found for the amount of $\mathrm{V}-\mathrm{H}^{+}$ATPase proteins in salt-treated plants of Mozart but not in salt-treated plants of Desiree (Figure 5). To measure the protein amounts of the $\mathrm{V}-\mathrm{H}^{+}$-ATPase, we used antibodies to detect subunit A (see section "Materials and Methods" section). Subunit $\mathrm{A}$ is located in the cytosolic $\mathrm{V}_{1}$ domain of the $\mathrm{V}-\mathrm{H}^{+}$-ATPase protein and subunits located in the more stable $\mathrm{V}_{0}$ complex of the $\mathrm{V}-\mathrm{H}^{+}$-ATPase protein may be considered for measurements of protein amounts. For example, Baisakh et al. (2012) expressed subunit c1 from a halophyte grass Spartina alterniflora in rice and the SaVHAc1 expressing plants showed enhanced tolerance to salt stress. Furthermore, after salt treatment, transcript levels of subunit $c$ increased earlier than transcript levels of subunit A or B did in Mesembryanthemum crystallinum (Low et al., 1996). So, analysis of other $\mathrm{V}-\mathrm{H}^{+}$-ATPase subunits would further contribute to elucidate the differences of $\mathrm{V}-\mathrm{H}^{+}$-ATPase activity between Mozart and Desiree.

\section{Substrate-Dependent Vacuolar $\mathrm{H}^{+}$ Transport Shows Varying Results Among Species and Tissues}

The effect of salt on vacuolar ATP- and PPi-dependent $\mathrm{H}^{+}$transport has been extensively studied in the last decades for many plant species, with varying results. One study with rice callus lines differing in salt tolerance showed a strong increase in vacuolar pump activity when salt-treated and more so in the salt tolerant lines (Pons et al., 2011). The halophytes
M. crystallinum and Suaeda salsa showed a salt-dependent increase in V-H ${ }^{+}$ATPase activity (Barkla et al., 1995; Qiu et al., 2007), while in Cucumis sativus ATP- and PPi-dependent proton transport decreased in roots after $50 \mathrm{mM} \mathrm{NaCl}$ treatment (Kabala and Klobus, 2008). In tonoplast vesicles derived from roots of the moderate salt tolerant sunflower (Helianthus annuus), ATP- and PPi-dependent proton transport increased in plants treated with $150 \mathrm{mM} \mathrm{NaCl}$ (Ballesteros et al., 1996). Salt treatment induced $\mathrm{V}-\mathrm{H}^{+}$-ATPase and $\mathrm{V}-\mathrm{H}^{+}$-PPase activity in vesicles derived from Spinacia oleracea, whereas $\mathrm{V}-\mathrm{H}^{+}$-ATPase and $\mathrm{V}-\mathrm{H}^{+}$-PPase activity in Salicornia dolichostachya was not affected by salt treatment (Katschnig et al., 2014). These different and often contrasting results suggest major differences between species and tissues in the capacity to control vacuolar proton pump activity. It should be noted that the severity and length of the salt treatments varied among the above-mentioned studies, what may as well be a cause for variation in the results.

However, our results showed that in leaves of potato plants, vacuolar ATP- and PPi-dependent $\mathrm{H}^{+}$transport decreased after salt treatment (Figures 3,4), the amount of $\mathrm{V}-\mathrm{H}^{+}$-PPases and $\mathrm{V}-\mathrm{H}^{+}$-ATPases proteins decreased in Mozart but not in Desiree (Figure 5) and although transcripts of StVP2 were low, expression was induced in both cultivars after salt treatment (Figure 7). These results resemble previous findings for roots of wheat showing that $\mathrm{V}-\mathrm{H}^{+}-\mathrm{ATPase}-$, and $\mathrm{V}-\mathrm{H}^{+}$-PPase activity and $\mathrm{V}-\mathrm{H}^{+}$-ATPase-, and $\mathrm{V}$-PPase protein amount decreased, while expression of TaVP1 and TaVP2 increased upon salt stress (Wang et al., 2000, 2009). Recently, other functions besides generating a PMF for the $\mathrm{V}-\mathrm{H}^{+}$PPases have been reviewed, such as increased auxin fluxes, increased nutrient uptake, or increased carbohydrate metabolism (Schilling et al., 2017) and these functions may also contribute to growth during salt conditions.

\section{Activity of $\mathrm{Na}^{+} / \mathrm{H}^{+}$Antiport and $\mathrm{NHX}$ Expression in Response to Salt}

NHXs function in cellular $\mathrm{Na}^{+}-, \mathrm{K}^{+}$-homeostasis and are either targeted to the vacuole (Class I) or targeted to the pre-vacuoles (Class II) (Rodríguez-Rosales et al., 2009). Expression of multiple NHX isoforms of both classes in a variety of plant species improves salt tolerance (Rodríguez-Rosales et al., 2009; Agarwal et al., 2012) although this may not simply be due to enhanced $\mathrm{Na}^{+}$ accumulation into the central vacuole since NHX transporters show varying degrees of $\mathrm{Na}^{+} / \mathrm{H}^{+}$and $\mathrm{K}^{+} / \mathrm{H}^{+}$antiport activity (Barragan et al., 2012; Zhang et al., 2015). For example, SINHX2 confers $\mathrm{K}^{+} / \mathrm{H}^{+}$exchange and localizes to pre-vacuolar vesicles, but tomato plants with enhanced SINHX2 expression and the tomato $n h x 2$ null mutants were more- and less-salt tolerant, respectively (Rodríguez-Rosales et al., 2008). In addition, a $n h x 4$ null mutation in Arabidopsis showed enhanced tolerance to salt stress and lower $\mathrm{Na}^{+}$and higher $\mathrm{K}^{+}$levels than wild-type plants (Li et al., 2009).

The four StNHX transcripts analyzed in this study are homologs of the better characterized SINHX genes from tomato and the relative expression of the four isoforms in leaves of non-stressed tomato (Gálvez et al., 2012) and potato plants 
(Figure 7) is similar: SlNHX1 and SlNHX4 transcript levels are relatively low and high, respectively, and those of SINHX2 and SlNHX3 are intermediate. In our study, salt had no effect on StNHX1 expression of either cultivar, induced the expression of StNHX2 in Mozart, induced StNHX3 in Desiree and no effect of salt was found on expression of StNHX4 (Figure 7). It is difficult to translate changes in transcripts of a specific gene to changes in protein, let alone protein activity. Though, the relative moderate changes in expression of the NHX genes by salt are in line with our observation that the $V_{\max }$ of the $\mathrm{Na}^{+} / \mathrm{H}^{+}$antiport activity is not different between control and salt-treated plants (Figure 6) and this low activity may explain the general moderate salt tolerance found for potato. However, what is different when comparing the two cultivars and not in line with the NHX expression data is that the $V_{\max }$ for $\mathrm{Na}^{+} / \mathrm{H}^{+}$antiport activity is twofold higher in Desiree and the $K_{\mathrm{m}}$ for $\mathrm{Na}^{+}$is at least twofold lower in Desiree (Figure 6).

Higher NHXs abundance in Desiree and/or post-translational regulation of NHXs in Desiree may cause the observed differences in antiport activity and affinity for $\mathrm{Na}^{+}$. It has been proposed that protein-protein interaction, phosphorylation, and/or glycosylation of the C-terminus can differentially regulate the antiport activity of NHXs (Qiu et al., 2004; Bassil et al., 2012; Bassil and Blumwald, 2014). So far, a calmodulin-like protein (AtCaM15) was found to bind the C-terminus of AtNHX1 within the vacuolar lumen in yeast cells and modify the cation selectivity in a $\mathrm{Ca}^{2+}$ and $\mathrm{pH}$-dependent manner for either $\mathrm{K}^{+}$ or $\mathrm{Na}^{+}$(Yamaguchi et al., 2005). The authors suggested that in normal physiological conditions (high free vacuolar $\mathrm{Ca}^{2+}$ and $\mathrm{pH} \sim 5.5$ ) AtCam15 is bound to AtNHX1 rendering the

\section{REFERENCES}

Adem, G. D., Roy, S. J., Huang, Y., Chen, Z.-H., Wang, F., Zhou, M., et al. (2017). Expressing Arabidopsis thaliana V-ATPase subunit C in barley Hordeum vulgare improves plant performance under saline condition by enabling better osmotic adjustment. Funct. Plant Biol. 44, 1147-1159. doi: 10.1071/FP17133

Adem, G. D., Roy, S. J., Plett, D. C., Zhou, M., Bowman, J. P., and Shabala, S. (2015). Expressing AtNHX1 in barley (Hordium vulgare L.) does not improve plant performance under saline conditions. Plant Growth Regul. 77, 289-297. doi: 10.1007/s10725-015-0063-9

Agarwal, P., Shukla, P., Gupta, K., and Jha, B. (2012). Bioengineering for salinity tolerance in plants: state of the art. Mol. Biotechnol. 54, 102-123. doi: 10.1007/ s12033-012-9538-3

Aghaei, K., Ehsanpour, A. A., and Komatsu, S. (2009). Potato responds to salt stress by increased activity of antioxidant enzymes. J. Integr. Plant Biol. 51, 1095-1103. doi: 10.1111/j.1744-7909.2009.00886.x

Baisakh, N., RamanaRao, M. V., Rajasekaran, K., Subudhi, P., Janda, J., Galbraith, D., et al. (2012). Enhanced salt stress tolerance of rice plants expressing a vacuolar $\mathrm{H}+$-ATPase subunit $\mathrm{cl}$ (SaVHAc1) gene from the halophyte grass Spartina alterniflora Löisel. Plant Biotechnol. J. 10, 453-464. doi: 10.1111/j.1467-7652.2012.00678.x

Ballesteros, E., Donaire, J. P., and Belver, A. (1996). Effects of salt stress on H+ATPase and H+-PPase activities of tonoplast-enriched vesicles isolated from sunflower roots. Physiol. Plant. 97, 259-268. doi: 10.1034/j.1399-3054.1996. 970208.x

Barkla, B. J., Zingarelli, L., Blumwald, E., and Smith, J. A. C. (1995). Tonoplast $\mathrm{NA}+/ \mathrm{H}+$ Antiport activity and its energization by the vacuolar $\mathrm{H}+$-atpase in the halophytic plant Mesembryanthemum-crystallinum L. Plant Physiol. 109, 549-556. doi: 10.1104/pp.109.2.549 antiporter with a higher affinity for $\mathrm{K}^{+}$over $\mathrm{Na}^{+}$. Higher cytosolic $\mathrm{Na}^{+}$concentrations may lead to vacuolar alkalization and subsequently to the dissociation of AtCam 15 from AtNHX1 resulting in a higher affinity for $\mathrm{Na}^{+}$over $\mathrm{K}^{+}$(Yamaguchi et al., 2005).

Different phosphorylation sites in the C-terminus of NHX proteins appear to be present in many sequenced plant species so far, but await further functional analysis (Bassil et al., 2012). For example, sequencing the NHXs and homologs of AtCaM15 from both potato cultivars may elucidate differences in these regulatory sites and reveal clues about the overall lower $\mathrm{Na}^{+} / \mathrm{H}^{+}$antiport activity found for Mozart.

\section{AUTHOR CONTRIBUTIONS}

RJ and AdB designed the experiments. RJ conducted the experiments. RJ and AdB wrote the manuscript.

\section{FUNDING}

This study was supported by a grant from STW, Netherlands (Grant No. 07912).

\section{SUPPLEMENTARY MATERIAL}

The Supplementary Material for this article can be found online at: https://www.frontiersin.org/articles/10.3389/fpls.2018.00737/ full\#supplementary-material

Barragan, V., Leidi, E. O., Andres, Z., Rubio, L., De Luca, A., Fernandez, J. A., et al. (2012). Ion Exchangers NHX1 and NHX2 mediate active potassium uptake into vacuoles to regulate cell turgor and stomatal function in Arabidopsis. Plant Cell 24, 1127-1142. doi: 10.1105/tpc.111.095273

Bassil, E., and Blumwald, E. (2014). The ins and outs of intracellular ion homeostasis: NHX-type cation/H+ transporters. Curr. Opin. Plant Biol. 22, 1-6. doi: 10.1016/j.pbi.2014.08.002

Bassil, E., Coku, A., and Blumwald, E. (2012). Cellular ion homeostasis: emerging roles of intracellular $\mathrm{NHX} \mathrm{Na}+/ \mathrm{H}+$ antiporters in plant growth and development. J. Exp. Bot. 63, 5727-5740. doi: 10.1093/jxb/ers250

Bassil, E., Ohto, M.-A., Esumi, T., Tajima, H., Zhu, Z., Cagnac, O., et al. (2011). The Arabidopsis intracellular $\mathrm{Na}+/ \mathrm{H}+$ antiporters NHX5 and NHX6 are endosome associated and necessary for plant growth and development. Plant Cell 23, 224-239. doi: 10.1105/tpc.110.079426

Batelli, G., Massarelli, I., Van Oosten, M., Nurcato, R., Vannini, C., Raimondi, G., et al. (2012). Asgl is a stress-inducible gene which increases stomatal resistance in salt stressed potato. J. Plant Physiol. 169, 1849-1857. doi: 10.1016/j.jplph. 2012.07.004

Bonales-Alatorre, E., Shabala, S., Chen, Z.-H., and Pottosin, I. (2013). Reduced tonoplast fast-activating and slow-activating channel activity is essential for conferring salinity tolerance in a facultative halophyte, quinoa. Plant Physiol. 162, 940. doi: 10.1104/pp.113.216572

Eckardt, N. A., and Berkowitz, G. A. (2011). Functional analysis of Arabidopsis NHX antiporters: the role of the vacuole in cellular turgor and growth. Plant Cell 23, 3087-3088. doi: 10.1105/tpc.111.230914

Fukuda, A., Chiba, K., Maeda, M., Nakamura, A., Maeshima, M., and Tanaka, Y. (2004). Effect of salt and osmotic stresses on the expression of genes for the vacuolar $\mathrm{H}+$-pyrophosphatase, $\mathrm{H}+$-ATPase subunit $\mathrm{A}$, and $\mathrm{Na}+/ \mathrm{H}+$ antiporter from barley. J. Exp. Bot. 55, 585-594. doi: 10.1093/jxb/erh070 
Gálvez, F. J., Baghour, M., Hao, G., Cagnac, O., Rodríguez-Rosales, M. P., and Venema, K. (2012). Expression of LeNHX isoforms in response to salt stress in salt sensitive and salt tolerant tomato species. Plant Physiol. Biochem. 51, 109-115. doi: 10.1016/j.plaphy.2011.10.012

Gaxiola, R. A., Li, J., Undurraga, S., Dang, L. M., Allen, G. J., Alper, S. L., et al. (2001). Drought-and salt-tolerant plants result from overexpression of the AVP1 H+-pump. Proc. Natl. Acad. Sci. U.S.A. 98, 11444-11449. doi: 10.1073/ pnas. 191389398

He, X., Huang, X., Shen, Y., and Huang, Z. (2014). Wheat V-H+-ATPase subunit genes significantly affect salt tolerance in Arabidopsis thaliana. PLoS One 9:e86982. doi: 10.1371/journal.pone.0086982

Hmida-Sayari, A., Costa, A., Leone, A., Jaoua, S., and Gargouri-Bouzid, R. (2005). Identification of salt stress-induced transcripts in potato leaves by cDNA-AFLP. Mol. Biotechnol. 30, 31-39. doi: 10.1385/MB:30:1:031

Jaarsma, R., de Vries, R. S. M., and de Boer, A. H. (2013). Effect of salt stress on growth, $\mathrm{Na}+$ accumulation and proline metabolism in potato (Solanum tuberosum) cultivars. PLoS One 8:e60183. doi: 10.1371/journal.pone.0060183

Jiang, X., Leidi, E. O., and Pardo, J. M. (2010). How do vacuolar NHX exchangers function in plant salt tolerance? Plant Signal. Behav. 5, 792-795.

Kabala, K., and Klobus, G. (2008). Modification of vacuolar proton pumps in cucumber roots under salt stress. J. Plant Physiol. 165, 1830-1837. doi: 10.1016/ j.jplph.2008.01.003

Katschnig, D., Jaarsma, R., Almeida, P., Rozema, J., and Schat, H. (2014). Differences in proton pumping and $\mathrm{Na} / \mathrm{H}$ exchange at the leaf cell tonoplast between a halophyte and a glycophyte. AoB Plants 6:lu023. doi: 10.1093/aobpla/ plu023

Krebs, M., Beyhl, D., Görlich, E., Al-Rasheid, K. A. S., Marten, I., Stierhof, Y.-D., et al. (2010). Arabidopsis V-ATPase activity at the tonoplast is required for efficient nutrient storage but not for sodium accumulation. Proc. Natl. Acad. Sci. U.S.A. 107, 3251-3256. doi: 10.1073/pnas.0913035107

Legay, S., Lamoureux, D., Hausman, J.-F., Hoffmann, L., and Evers, D. (2009). Monitoring gene expression of potato under salinity using cDNA microarrays. Plant Cell Rep. 28, 1799-1816. doi: 10.1007/s00299-009-0780-5

Levy, D., and Veilleux, R. E. (2007). Adaptation of potato to high temperatures and salinity - A review. Am. J. Potato Res. 84, 487-506. doi: 10.1038/hdy.2008.132

Li, H.-T., Liu, H., Gao, X.-S., and Zhang, H. (2009). Knock-out of Arabidopsis AtNHX4 gene enhances tolerance to salt stress. Biochem. Biophys. Res. Commun. 382, 637-641. doi: 10.1016/j.bbrc.2009.03.091

Low, R., Rockel, B., Kirsch, M., Ratajczak, R., Hortensteiner, S., Martinoia, E., et al. (1996). Early salt stress effects on the differential expression of vacuolar H+ATPase genes in roots and leaves of Mesembryanthemum crystallinum. Plant Physiol. 110, 259-265. doi: 10.1104/pp.110.1.259

Maeshima, M. (2000). Vacuolar H+-pyrophosphatase. Biochim. Biophys. Acta 1465, 37-51. doi: 10.1016/S0005-2736(00)00130-9

Mohammed, S. A., Nishio, S., Takahashi, H., Shiratake, K., Ikeda, H., Kanahama, K., et al. (2012). Role of Vacuolar H+-inorganic pyrophosphatase in tomato fruit development. J. Exp. Bot. 63, 5613-5621. doi: 10.1093/jxb/ers213

Muller, P. Y., Janovjak, H., Miserez, A. R., and Dobbie, Z. (2002). Processing of gene expression data generated by quantitative real-time RT-PCR. Biotechniques 32, 1372-1379.

Munns, R., and Tester, M. (2008). Mechanisms of salinity tolerance. Annu. Rev. Plant Biol. 59, 651-681. doi: 10.1146/annurev.arplant.59.032607.092911

Nicot, N., Hausman, J. F., Hoffmann, L., and Evers, D. (2005). Housekeeping gene selection for real-time RT-PCR normalization in potato during biotic and abiotic stress. J. Exp. Bot. 56, 2907-2914. doi: 10.1093/jxb/eri285

Pardo, J. M., and Rubio, F. (2011). Na+ and K+ transporters in plant signaling. Signal. Commun. Plants 7, 65-98. doi: 10.1007/978-3-642-14369-4_3

Pons, R., Cornejo, M.-J. S., and Sanz, A. (2011). Differential salinity-induced variations in the activity of $\mathrm{H}+$-pumps and $\mathrm{Na}+/ \mathrm{H}+$ antiporters that are involved in cytoplasm ion homeostasis as a function of genotype and tolerance level in rice cell lines. Plant Physiol. Biochem. 49, 1399-1409. doi: 10.1016/j. plaphy.2011.09.011

Qiu, N., Chen, M., Guo, J., Bao, H., Ma, X., and Wang, B. (2007). Coordinate upregulation of $\mathrm{V}-\mathrm{H}+-\mathrm{ATPase}$ and vacuolar $\mathrm{Na}+/ \mathrm{H}+$ antiporter as a response to $\mathrm{NaCl}$ treatment in a C3 halophyte Suaeda salsa. Plant Sci. 172, 1218-1225. doi: 10.1016/j.plantsci.2007.02.013

Qiu, Q.-S., Guo, Y., Quintero, F. J., Pardo, J. M., Schumaker, K. S., and Zhu, J.K. (2004). Regulation of vacuolar $\mathrm{Na}+/ \mathrm{H}+$ exchange in Arabidopsis thaliana by the salt-overly-sensitive (SOS) pathway. J. Biol. Chem. 279, 207-215. doi: 10.1074/jbc.M307982200

Queiros, F., Fontes, N., Silva, P., Almeida, D., Maeshima, M., Geros, H., et al. (2009). Activity of tonoplast proton pumps and $\mathrm{Na}+/ \mathrm{H}+$ exchange in potato cell cultures is modulated by salt. J. Exp. Bot. 60, 1363-1374. doi: 10.1093/jxb/ erp011

Reguera, M., Bassil, E., Tajima, H., Wimmer, M., Chanoca, A., Otegui, M. S., et al. (2015). pH Regulation by NHX-Type antiporters is required for receptormediated protein trafficking to the vacuole in Arabidopsis. Plant Cell 27, 1200-1217. doi: 10.1105/tpc.114.135699

Rodríguez-Rosales, M. P., Gálvez, F. J., Huertas, R., Aranda, M. N., Baghour, M., Cagnac, O., et al. (2009). Plant NHX cation/proton antiporters. Plant Signal. Behav. 4, 265-276. doi: 10.4161/psb.4.4.7919

Rodríguez-Rosales, M. P., Jiang, X., Gálvez, F. J., Aranda, M. N., Cubero, B., and Venema, K. (2008). Overexpression of the tomato K+/H+ antiporter LeNHX2 confers salt tolerance by improving potassium compartmentalization. New Phytol. 179, 366-377. doi: 10.1111/j.1469-8137.2008.02461.x

Roy, S. J., Negrao, S., and Tester, M. (2014). Salt resistant crop plants. Curr. Opin. Biotechnol. 26, 115-124. doi: 10.1016/j.copbio.2013.12.004

Schilling, R. K., Marschner, P., Shavrukov, Y., Berger, B., Tester, M., Roy, S. J., et al. (2014). Expression of the Arabidopsis vacuolar H+-pyrophosphatase gene (AVP1) improves the shoot biomass of transgenic barley and increases grain yield in a saline field. Plant Biotechnol. J. 12, 378-386. doi: 10.1111/pbi.12145

Schilling, R. K., Tester, M., Marschner, P., Plett, D. C., and Roy, S. J. (2017). AVP1: one protein, many roles. Trends Plant Sci. 22, 154-162. doi: 10.1016/j.tplants. 2016.11.012

Schumacher, K., and Krebs, M. (2010). The V-ATPase: small cargo, large effects. Curr. Opin. Plant Biol. 13, 724-730. doi: 10.1016/j.pbi.2010.07.003

Shabala, S., and Mackay, A. (2011). Ion Transport in Halophytes. Adv. Bot. Res. 57, 151-199. doi: 10.1016/B978-0-12-387692-8.00005-9

Wang, B. S., Ratajczak, R., and Zhang, J. H. (2000). Activity, amount and subunit composition of vacuolar-type $\mathrm{H}+$-ATPase and $\mathrm{H}+$-PPase in wheat roots under severe $\mathrm{NaCl}$ stress. J. Plant Physiol. 157, 109-116. doi: 10.1016/S0176-1617(00) 80143-1

Wang, Y., Xu, H., Zhang, G., Zhu, H., Zhang, L., Zhang, Z., et al. (2009). Expression and responses to dehydration and salinity stresses of V-PPase gene members in wheat. J. Genet. Genomics 36, 711-720. doi: 10.1016/S1673-8527(08)60164-2

Yamaguchi, T., Aharon, G. S., Sottosanto, J. B., and Blumwald, E. (2005). Vacuolar $\mathrm{Na}+/ \mathrm{H}+$ antiporter cation selectivity is regulated by calmodulin from within the vacuole in a $\mathrm{Ca} 2+-$ and $\mathrm{pH}$-dependent manner. Proc. Natl. Acad. Sci. U.S.A. 102, 16107-16112. doi: 10.1073/pnas.0504437102

Zhang, M., Fang, Y., Liang, Z., and Huang, L. (2012). Enhanced expression of vacuolar $H$ sup sup-ATPase subunit $E$ in the roots is associated with the adaptation of italic Broussonetia papyrifera italic to salt stress. PLoS One 7:e48183. doi: 10.1371/journal.pone.0048183

Zhang, Y.-M., Zhang, H.-M., Liu, Z.-H., Li, H.-C., Guo, X.-L., and Li, G.-L. (2015). The wheat NHX antiporter gene TaNHX2 confers salt tolerance in transgenic alfalfa by increasing the retention capacity of intracellular potassium. Plant Mol. Biol. 87, 317-327. doi: 10.1007/s11103-014-0278-6

Conflict of Interest Statement: The authors declare that the research was conducted in the absence of any commercial or financial relationships that could be construed as a potential conflict of interest.

Copyright (C) 2018 Jaarsma and de Boer. This is an open-access article distributed under the terms of the Creative Commons Attribution License (CC BY). The use, distribution or reproduction in other forums is permitted, provided the original author(s) and the copyright owner are credited and that the original publication in this journal is cited, in accordance with accepted academic practice. No use, distribution or reproduction is permitted which does not comply with these terms. 